\title{
Built Infrastructure Conditions Mediate the Relationship between Stakeholders Attributes and Flood Damage: An Empirical Case Study
}

\author{
Mohammad Mojtahedi *(D) and Bee Lan Oo \\ School of Built Environment, UNSW Sydney, Sydney, NSW 2052, Australia; bee.oo@unsw.edu.au \\ * Correspondence: m.mojtahedi@unsw.edu.au
}

Citation: Mojtahedi, M.; Oo, B.L. Built Infrastructure Conditions

Mediate the Relationship between Stakeholders Attributes and Flood Damage: An Empirical Case Study. Sustainability 2021, 13, 9739. https:// doi.org/10.3390/su13179739

Academic Editors: Wen Cheng Liu and Marc A. Rosen

Received: 9 July 2021

Accepted: 25 August 2021

Published: 30 August 2021

Publisher's Note: MDPI stays neutral with regard to jurisdictional claims in published maps and institutional affiliations.

Copyright: (C) 2021 by the authors. Licensee MDPI, Basel, Switzerland. This article is an open access article distributed under the terms and conditions of the Creative Commons Attribution (CC BY) license (https:// creativecommons.org/licenses/by/ $4.0 /)$.

\begin{abstract}
Most of the previous research has tended to focus on the impact of flood characteristics on built infrastructure damage rather than to investigate the condition of the infrastructure and stakeholders' capacity to manage flood risks. The role of stakeholder attributes, such as the power, legitimacy, and urgency of local governments, in reducing the impact of disasters on built infrastructure remains ambiguous. Stakeholders' organizational attributes, together with socio-economic and built infrastructure conditions, need to be considered to provide a better understanding of how to reduce disaster risk. The main aim of this research was to empirically investigate the mediating role of socio-economic and infrastructure conditions in the direct relationship between stakeholders' attributes and economic damage to road infrastructure from flooding. Survey data collected from local governments in New South Wales, Australia and historical data for over 20 years from archive databases were analyzed using structural equation modeling with the partial least squares estimation approach. The results showed that socio-economic and infrastructure conditions have significant mediating effects on the direct relationship between stakeholders' attributes and flood damage. Engaging stakeholders proactively empowers legitimate stakeholders in urgent conditions, and this is essential to reduce the economic impact of flood disasters and to better manage road infrastructure. Finally, to better manage flood risks, local governments need to improve their capacity of power, legitimacy, and urgency; state and federal governments need to improve the socio-economic conditions of the communities; and the transport infrastructure authorities need to develop long-term solutions for resilient roads and bridges.
\end{abstract}

Keywords: disaster risk; resilient infrastructure; stakeholders management

\section{Introduction}

Critical built infrastructures are physical assets that are essential for the functioning of a society and economy such as power plants, water and wastewater systems, telecommunications, transportation networks and systems, healthcare, and public health. Built infrastructure can be at risk of economic damage from natural hazards [1]. Risk can be described as the possibility of a natural hazard taking place and it involves uncertainty about the impacts of a natural hazard with respect to society, economy, and the built environment. Transport infrastructure in particular is exposed to extremes in temperature, river floods, and storm surges, and is susceptible to damage [2]. Flooding is the most severe weather threat and is regarded as the costliest type of disaster particularly for critical built infrastructure. Reducing flood risks and creating resilient built infrastructure have gained increasing recognition from policymakers, construction practitioners, and scholars. Resilient infrastructure is particularly important due to increased risks from climate change and fast-growing urbanization, which exacerbate the vulnerability of infrastructure [3,4]. For example, the most recent global and international disaster risk management framework such as the Sendai Framework for Disaster Risk Reduction 2015-2030 has focused on resilient built infrastructure for a substantial reduction in disaster risk and losses of physical 
assets [5]. The exposure, vulnerability, and impact to transport infrastructure of floods vary by region, location, elevation, and condition of the infrastructure [6]. Roads, bridges, culverts, basins, and drainage are the most vulnerable elements in transport infrastructure in those areas with projected increases in flooding due to climate change.

Successful flood risk management for resilient transport infrastructure requires flood risk to be effectively managed by stakeholders $[7,8]$. Stakeholders are individuals, entities, communities, or firms who may influence or be impacted by the results of floods (adopted from [9]). Anyone engaged in managing flood risks, or whose interests may be adversely affected by a flood risk, can be considered a stakeholder in flood risk management, including government (such as federal, state, and local in Australia), communities, emergency organizations, financial institutions, and insurance companies.

In accordance with stakeholder theory developed by Freeman [9], power, legitimacy, and urgency are three critical stakeholder attributes that play an essential role in organizational success and are pivotal attributes for engaging stakeholders proactively in enhancing organizations' productivity [10-12]. The power of a stakeholder is its ability to mobilize social and political forces, as well as its ability to pull out resources from the organization in disaster situations. Most research in the field of disaster risk management has only focused on the impact of disasters on socio-economic conditions and infrastructure independently, and little research has evaluated the role of stakeholder attributes in reducing damage to communities and built infrastructure.

Although some scholars have studied stakeholder engagement in disaster risk reduction [13], only a limited number of studies have investigated stakeholder attributes of power, legitimacy, and urgency in managing flood damage to critical transport infrastructure $[14,15]$. For example, Bosher et al. [7] showed that stakeholders with high access to essential social resources are the strongest stakeholders against natural hazards, and an empirical study conducted by Mojtahedi and Oo [15] suggested that stakeholders with more power, legitimacy, and urgency attributes have managed disaster recovery projects with better performance. However, this paper focused on the role of stakeholder attributes on flood transport infrastructure damage, which has been absent from previous studies.

In addition, Mojtahedi and Oo [14] reviewed the literature on stakeholder engagement in disaster risk management and found that stakeholder attributes of power, legitimacy, and urgency are significant factors in reducing disaster risks in the mitigation, preparedness, response, and recovery phases of disaster risk management. Power allows a stakeholder to apply its own will despite resistance from other stakeholders in disaster risk reduction. The power of a stakeholder is its capability to support the entity to drive social, economic, and political forces, as well as its capability to deploy resources from the organization in the event of a disaster. Legitimacy provides the opportunity to a stakeholder to understand the risk related to its organization in disaster risk management. Urgency is the ability of a stakeholder to warn and inform for rapid actions in disaster risk management [14].

This paper investigated the role of the attributes of a major stakeholder, Australian local councils, in managing flood damage to roads and bridges, including basins, barriers, culverts, levees, and drainage. The objectives of the empirical research were to:

1. Develop a conceptual framework on the capacity of local councils' attributes for controlling flood damage to transport infrastructure;

2. Investigate the relationships and collective impact of local councils' attributes in managing the economic impact of flood damage to transport infrastructure;

3. Evaluate the mediating impacts of transport infrastructure and socio-economic conditions on the relationship between stakeholder attributes and flood damage to transport infrastructure.

The results can help local councils prioritize transport infrastructure development and maintainable criteria and make strategic decisions on critical road infrastructure planning such as constructing for a resilient future and increasing the safety of transport infrastructure during disasters, particularly reducing evacuation time. 


\section{Impact of Flooding, Stakeholder Attributes, and Solutions for Resilient Built Environment}

\subsection{The Impact of Flooding on the Built Environment}

Based on the World Disasters Report [16], over 2 billion people globally were affected by natural hazards in the last decade. Extreme weather events associated with climate change have been the dominant disasters over the past 20 years, with $91 \%$ of all disasters caused by floods, storms, droughts, and heatwaves between 1998 and 2017. Floods are the most frequent and life-threatening of all natural hazards, making up $43 \%$ of all recorded natural hazards events, and affecting 850 million people from 1998 to 2018 [17].

Much of the Australian built environment, particularly critical road infrastructure, is either in the cyclone belt of Australia or situated close to the ocean or rivers [15]. Therefore, the Australian built environment is becoming more vulnerable to climate change effects such as sea level rise and floods. With rapid urbanization, the built environment becomes more vulnerable to natural hazards in terms of community loss, and economic and infrastructure damage [13], especially in developed nations that use increasingly complicated design and sophisticated technology.

Floods in south Queensland and north New South Wales, Australia in 2010/2011 had a calamitous impact on almost $10,000 \mathrm{~km}$ of the road network and $5000 \mathrm{~km}$ of the rail network and severely damaged around 100 bridges, culverts, basins, and drainage systems. In 2013, a localized flood in the Lockyer Valley region in southeast Queensland, Australia, damaged 43 of the total 46 bridges in that location [18].

Australia is increasingly susceptible to anticipated increases in the extreme weather events associated with climate change such as floods, storms, tropical cyclones, heatwaves, and bushfires. The frequency, scale, and intensity of extreme weather events are increasing in Australia [19] and built infrastructure is especially vulnerable. The World Disasters Report 2018, prepared by the Red Cross, ranked Australia 10th in the world for the cost of damage caused by disasters between 2008 and 2017. By 2050, the economic cost of natural hazards is estimated to exceed USD 22 billion per year in Australia. Widespread flooding in 2010/2011 in Australia caused an estimated AUD 14 billion in transport infrastructure damage alone [20]. In 2017, Cyclone Debbie in Queensland caused USD 2.7 billion in damage and 14 deaths, primarily as a result of extreme flooding. From 1967 to 2013, Queensland and New South Wales recorded the highest natural hazard losses associated with climate change of USD 37 billion and USD 34 billion, respectively (Handmer et al., 2018). In February 2019, flooding in Townsville caused severe damage to road networks, businesses, and communities and, by 22 February 2019, more than 21,000 claims were lodged with estimated insurance losses of almost USD 0.75 billion [21].

Recent floods in Australia have accentuated the vulnerability of the built environment to unprecedented challenges due to the uncertainty of extreme weather events caused by climate change and sea level rise. Flood risk is associated with human interactions with floodplains, and the exposure and vulnerability to flood hazards reflect human activities such as developing cities on floodplains (e.g., [1,8,13]). Floods have severe impacts on the built environment such as residential and commercial buildings, schools, hospitals, train stations, roads, and bridges. Structures of buildings can be eroded or have their structural and nonstructural components destroyed by flooding and debris. All types of built environment, including road infrastructure, train platforms, airports, utility infrastructure (e.g., electrical, water, sewerage, and stormwater), and telecommunication systems, are susceptible to damage from flooding. Human-made structures and development may alter the paths, depths, and velocities of flood flow, and add debris to floodwaters, so humanmade development can exacerbate the magnitude of the damage [22]. Transport infrastructure has become much more vulnerable to unexpected severe weather events caused by the effects of climate change such as cyclones, storms, and floods [23-25].

Although previous studies have focused on the impact of natural hazards on residential and commercial buildings, transport infrastructure is more vulnerable to extreme weather events, such as storms and floods [2]. The research to date has tended to focus 
on the relationship between flood characteristics and flood damage rather than paying attention to the role of stakeholders' capabilities and attributes on flood damage. There is still inadequate evidence to support that key stakeholders are playing a proactive role in managing floods in the built environment, and empirical studies on stakeholder engagement are still absent in the flood risk management context. This study, therefore, focused on the impact of flooding on transport infrastructure considering stakeholder attributes.

\subsection{Stakeholder Attributes and Theory}

Effective stakeholder engagement in disaster risk management is an important component in reducing the impact of disasters on the built environment, and plays a key role in mitigation, preparedness response, and recovery. The United Nation's Sendai Framework for Disaster Risk Reduction has emphasized on the role of effective stakeholder engagement in advocating for resilient communities and the built environment. In addition, the Sendai Framework has focused on stakeholder engagement for better understanding disaster risk, strengthening disaster risk governance to manage disaster risk, investing in disaster risk reduction for resilience, and enhancing disaster preparedness for effective response and to "Build Back Better" in recovery, rehabilitation, and reconstruction [5].

However, little attention has been paid to stakeholders' approaches in disaster risk management. For example, in the United States, Oulahen et al. [26] investigated the role of key attributes of institutional capacity, including institutional arrangements, financial resources, staff capabilities, technical competencies, and leadership and managerial competencies to disaster management and mitigation. The organizational capacity of an organization to fulfil its mission through a blend of sound management and strong governance is a significant factor contributing to effective disaster risk management.

However, the role of stakeholder attributes and stakeholder theory have not been investigated in disaster risk management studies in the context of the built environment, particularly transport infrastructure. Mojtahedi and Oo [14] studied the effect of stakeholder attributes on post-disaster reconstruction performance in New South Wales, Australia and found that powerful, legitimate, and urgent stakeholders have managed post-disaster reconstruction projects with better performance in terms of time and cost; however, they have not shown how the stakeholder attributes could also reduce the impact of natural hazards on the built environment.

Freeman [9] introduced stakeholder theory with three key attributes for each stakeholder: power, legitimacy, and urgency. The power of a stakeholder enables them to make decisions and allocate resources in any event, particularly in crisis situations [27,28]. Legitimacy allows a stakeholder to withstand any risks, including opportunities and threats associated with the organization with logic and justification [12]. Urgency is the degree to which a stakeholder coordinates immediate actions and responds to risk at short notice [11,27]. The attributes of power, legitimacy, and urgency assist stakeholders in making a decision either proactively or reactively in disaster risk management. Figure 1 shows stakeholder proactive and reactive engagement in different flood risk management phases. A proactive approach includes tasks that are planned in the mitigation phase, and activities that are conducted in the preparedness phase by stakeholders before a natural hazard. A reactive approach includes response and recovery tasks that are executed by stakeholders during, and after a natural hazard [2,15,29].

Olander [27] amalgamated the power, legitimacy, and urgency attributes in Freeman's stakeholder theory to propose dynamism in the systematic identification of stakeholders. In addition, Mysiak et al. [30] showed that stakeholders with a higher degree of power will be the stronger stakeholders in reducing disaster risks. For a reactive approach, however, urgency helps stakeholders to respond to disaster in a more timely manner during or after disasters [8]. 


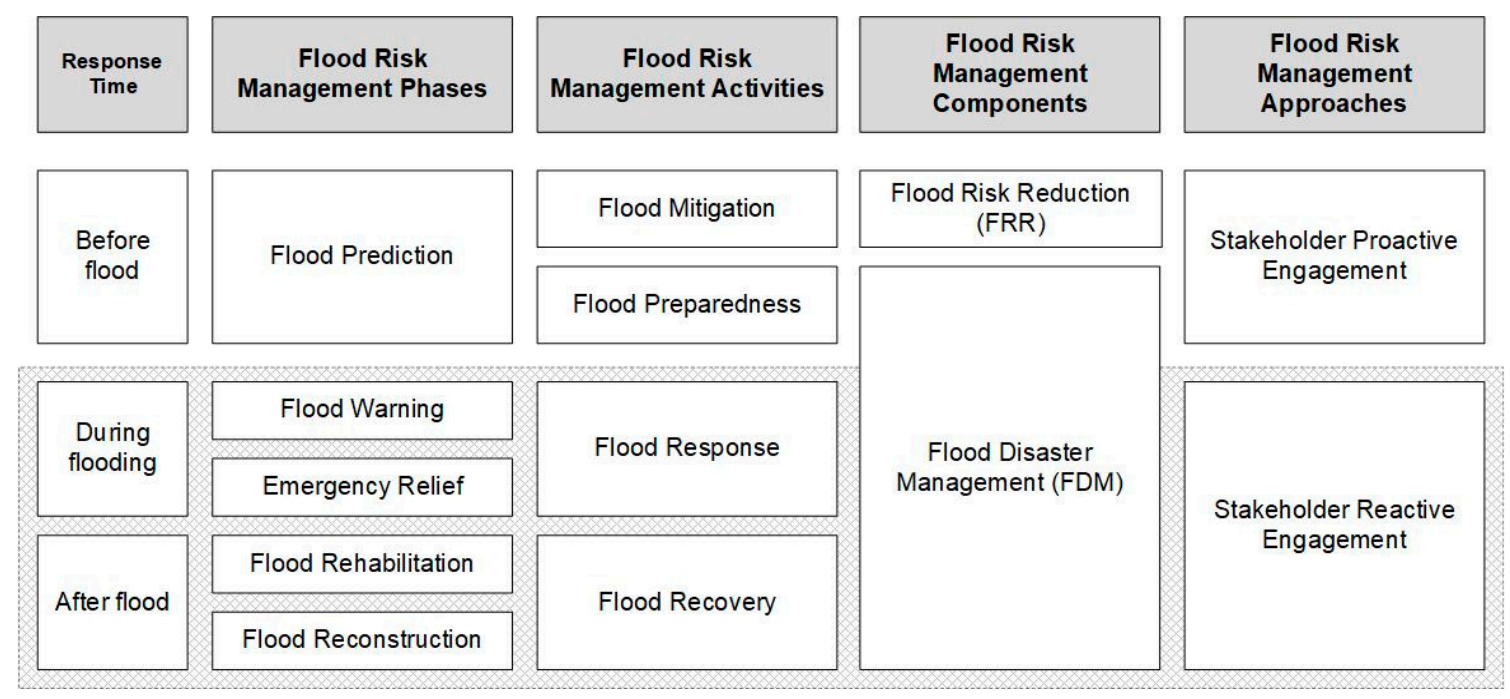

Figure 1. Stakeholder proactive and reactive engagement in flood risk management (adapted from [14,29]).

Stakeholder attributes enable policymakers to classify stakeholders into dormant, discretionary, demanding, dominant, dangerous, dependent, and definitive in managing disaster risks [15]. Stakeholder theory, therefore, is the pillar for proactive engagement of the stakeholders in disaster risk management. However, there have been no empirical studies on the role of stakeholder attributes in reducing flood damage in the built environment. Therefore, this paper examined the role of stakeholder attributes in reducing flood damage on transport infrastructure. The next section presents the conceptual framework to evaluate the role of socio-economic conditions and stakeholder attributes in reducing flood damage to roads and bridges in both flood risk reduction (mitigation phase) and flood disaster management (preparedness, response, and recovery phases).

\subsection{Gaps: Solutions and Directions for Further Changes}

While this study's literature review provides important insights into research on flood risk management in transport infrastructure in general, and stakeholder attributes and approaches in particular, it also highlights several research gaps that can pave the way for promising further changes. First, power, legitimacy, and urgency are changing variables and most likely vary among different stakeholders. By reviewing previous studies, it was found that the classification of stakeholders introduced by Freeman [9] and later developed by Mitchel et al. [11] has a significant role in determining why stakeholders have different approaches to flood disasters in reducing risks and improving the resilience of transport infrastructure. Second, although this study's literature review scrutinized the role of stakeholder attributes in managing flood risk management, it would be useful to explore stakeholder attributes in more detail, such as how to identify and enhance power, legitimacy, and urgency in stakeholders with limited or minimum resources to realize the full potential advantages of stakeholder capacities and capabilities to manage flood risk for the resilient built environment.

\section{Conceptual Framework: The Role of Stakeholders' Attributes in Reducing Flood Damage to Road Infrastructure}

Based on a review of literature, Figure 2 shows the conceptual framework for investigating the role of stakeholders in managing flood damage in transport infrastructure and the inter-relationships between various variables. It includes five constructs: (1) flood characteristics (FC); (2) flood damage (FD); (3) socio-economic condition (SE); (4) transport infrastructure condition (TI); and (5) stakeholder attributes (SE). There are 28 measurement indicators for these five constructs that are extracted from the literature review. Flood characteristics are essential factors that have been used to define the damage caused by 
flood disasters. Frequency, location, and socio-economic characteristics tend to exacerbate the impacts of disasters on both communities and the built environment [31], and the type of disaster is a reliable predictor of specific disaster damage [32]. Merz et al. [33] proposed that flood type, the flood-generating process, hydrological response, location, density, and frequency are the most important characteristics of flood disasters. Finally, some studies have confirmed that flood type, severity, and frequency are the most important characteristics in predicting flood damage [2,34-36].

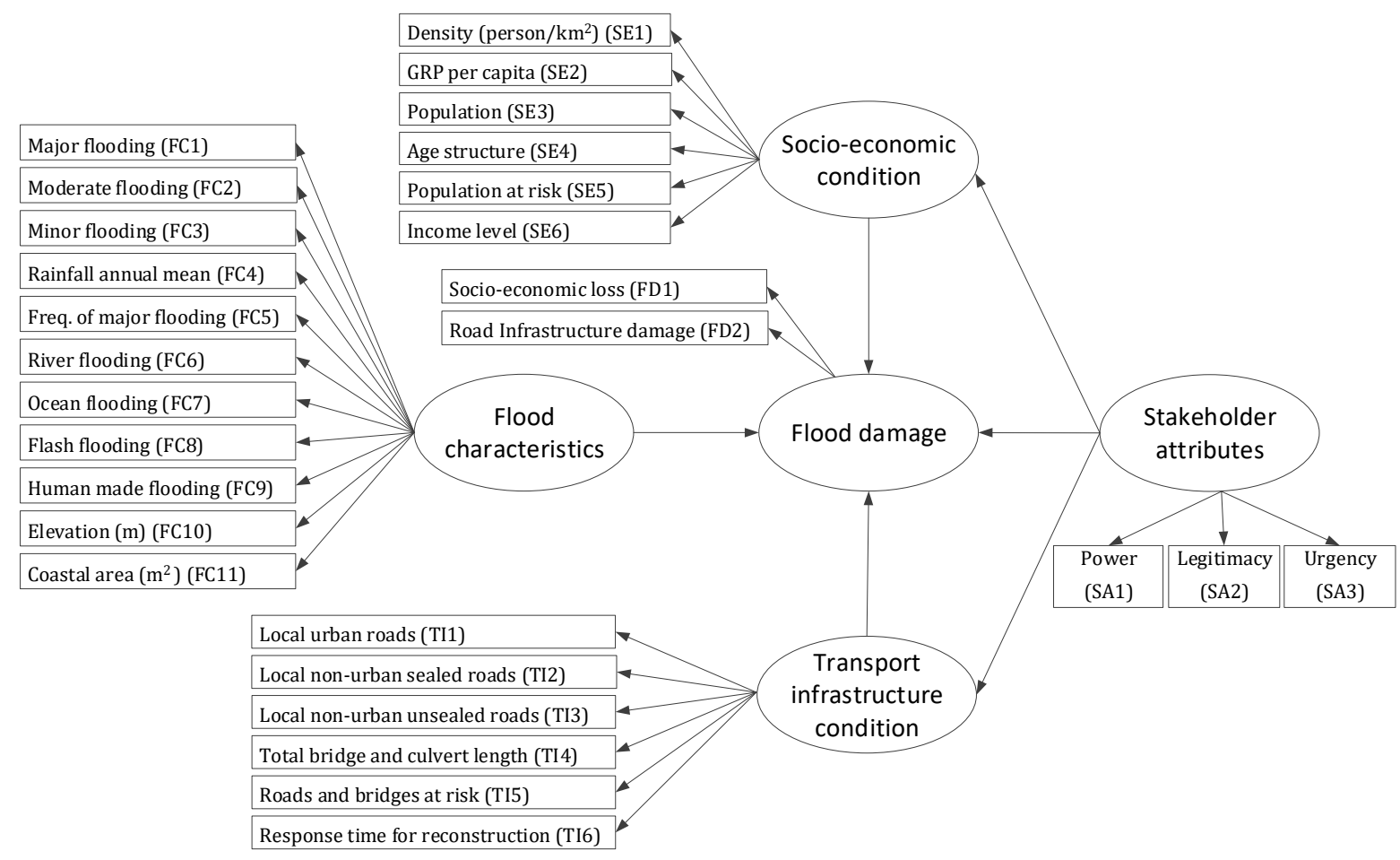

Figure 2. Conceptual framework for the impact of stakeholder attributes in reducing flood damage in transport infrastructure.

The socio-economic condition describes the exposure and vulnerability of a region's economy and society to a disaster, recognizing the role of macroeconomic indicators [37] and population, age and elderliness, and income level [38].

In this study, the socio-economic condition is defined as a region's exposure and vulnerability to disaster based on the population at risk, density, income, Gross Regional Product (GRP), and age structure, based on the data available for NSW, Australia. Other pertinent measurement variables could be considered, depending on data availability.

Tangible flood damage has been measured by socio-economic loss, including death, injury, homelessness, impact on GRP, and diseases [39,40]. The built environment loss includes structural damage to buildings, roads and bridges, contents of buildings, loss of other infrastructure, and debris removal [41,42]. Socio-economic loss and transport infrastructure loss were used to measure flood damage in this research.

A large number of previous studies have examined the relationship between disaster characteristics and disaster damage [43-45]. For instance, Dalezios et al. [46] empirically showed that an increase in flood characteristics, including severity and frequency and a change in flood type from minor to major, increases flood damage to society, economy, buildings, and infrastructure. Therefore, in this study, flood characteristics were conceptualized as a flood damage contributor in terms of socio-economic and road and bridge economic damage. Thus, the following hypothesis was formulated:

Hypothesis 1 (H1). Flood characteristics have a direct effect on the vulnerability of roads and bridges to flood damage. 
Apart from a direct relationship between stakeholder attributes and flood damage, the socio-economic condition and transport infrastructure conditions most likely also play a mediating role in the relationship between stakeholder attributes and flood damage. Thus, the mediator effects of these relationships were formulated as in the following hypotheses:

Hypothesis 2 (H2). (a) The socio-economic and (b) transport infrastructure conditions mediate the relationship between stakeholder attributes and the vulnerability of roads and bridges to flood damage.

\section{Materials and Methods}

\subsection{Research Design and Sample Characteristics}

Quantitative research alongside a case study was selected as the research methodology for this study. The conceptual framework was tested in the state of New South Wales (NSW), which contains a quarter of the Australian transport network total length in kilometers and is one of the most vulnerable states in Australia for flooding, particularly of its roads and bridges [47]. Flood-prone areas in NSW, unlike other states, include both riverine and local overland flooding areas, which exacerbate the exposure of transport infrastructure to flood risks. Local councils were selected as stakeholders for the sampling frame because they are responsible for investing, constructing, maintaining, restoring, and upgrading a major portion of regional and local roads and bridges across NSW. As NSW is susceptible to flood damage, particularly its transport infrastructure, the proposed conceptual framework (Section 3) is important to the matter and is highly relevant to this study.

Primary and secondary data sources were collected for testing the conceptual framework. Historical archive data over a period of 20 years between 1992 and 2014 were collected from secondary data sources relevant to flood risk management in NSW transport infrastructure, including the Bureau of Meteorology and Australian Bureau of Statistics. The time period was chosen because data and information on flood disasters were not kept in local councils and NSW Roads and Maritime Services databases prior to 1992. It should also be noted that this time period covers the impacts of the devastating Australia 2010-2011 floods, where more than 1000 transport infrastructure reconstruction projects were initiated in NSW after the major flood event and local councils reflected their experiences in managing those recovery projects between 2011 and 2014.

Transport infrastructure damage was extracted from NSW Roads and Maritime Services databases with approximately 4000 records of post-flooding reconstruction projects from 1992 to 2014. While the data may be considered dated, it must be pointed out that the data are comprehensive with a wide time span of over 20 years that the local authority was able to provide for research purposes. The dataset is deemed representative as it contains as many as thousands of projects in different regions of the state of NSW and covers the major floor events in NSW. Indeed, a good mix of projects in the dataset provides a rewarding finding in this research. In addition, this rich dataset is valuable for the replication of studies by other researchers, including comparative studies with other collections of datasets from different countries.

Primary data were collected from stakeholders using a survey distributed to local councils across NSW. A survey is a relatively quick and effective method of collecting information from targeted samples [48]. As not all local councils are susceptible to flood disasters in NSW, the sampling frame focused on 75 local councils who are members of Flood Management Australia (FMA) indicating the councils that have been affected by flood disasters. FMA is an NGO committed to advancing appropriate development within floodplain areas and helping to reduce flood risks to life, property, and infrastructure.

In the survey, experts from local councils were asked to rate individual questions on their flood information and the stakeholder's attributes on a seven-point Likert scale. For example, they were asked to rate the extent to which their local council has adopted power, legitimacy, and urgency attributes for flood disaster risk management in transport infrastructure. The survey was pilot-tested by four local councils to ensure the face and content 
validity and assess the degree to which a construct had been precisely operationalized. The survey was amended and revised before it was officially distributed to the 75 local councils across NSW by email via a SurveyMonkey link.

With 37 local councils completing the survey, the response rate was $48 \%$. Respondents included floodplain civil and infrastructure engineers specializing in stormwater and flooding who were involved in drainage design, flood modeling, and water resources management. In addition, town planners specializing in environmental planning were involved in completing the survey. In addition, emergency management officers are responsible for coordinating the planning, implementation, and review of the Council's emergency management and flood management responsibilities in partnership with other emergency agencies and community organizations. Flood risk analyst and designers who were working at Councils and closely working with engineers, project managers, and emergency management officers were also involved. Table 1 shows the respondents' profile in terms of field of work and years of experience in floodplain risk management.

Table 1. Summary of survey respondents' profile $(n=37)$.

\begin{tabular}{ccc}
\hline Attributes & Profile & Frequency (\%) \\
\hline \multirow{3}{*}{ Field of work } & Civil and infrastructure engineer & $12(33 \%)$ \\
& Construction project manager & $11(29 \%)$ \\
& Emergency management officer & $7(18 \%)$ \\
& Flood risk analyst & $6(15 \%)$ \\
Experience & Designer & $2(5 \%)$ \\
& Less than 5 years & $13(35 \%)$ \\
& $6-10$ years & $6(15 \%)$ \\
& $11-15$ years & $7(20 \%)$ \\
& $16-20$ years & $3(8 \%)$ \\
& More than 20 years & $8(22 \%)$ \\
\hline
\end{tabular}

\subsection{Data Analysis Technique}

The research takes on a systematic approach that relies on an empirical investigation of observable phenomena. It uses statistical models to develop and employ hypotheses or theories regarding disaster risk management. The process of measurement is central to the success of this work. The primary and secondary data from the survey responses and disaster management databases were analyzed using the SmartPLS software package [49]. Partial least squares structural equation modeling (PLS-SEM) was selected as the analytical technique because it works easily and effectively with a small sample dataset and complex models, and it also requires no assumptions for data distributions [50]. PLS-SEM is also a very powerful technique at estimating parameters. PLS-SEM is an advanced data analysis technique that incorporates aspects of factor analysis and regression to examine relationships between constructs such as independent and dependent variables at the same time.

\section{Results}

\subsection{Evaluating Measurement Models}

The adequacy of measurement models was evaluated in PLS-SEM using the individual indicator reliability and convergent validity of the measures related to individual constructs [51]. The Fornell-Larcker criterion and cross-loadings were used to evaluate discriminant validity [52,53].

Table 2 shows that all loadings were greater than 0.7 , indicating acceptable indicator reliability [54]. Nonetheless, before removal, the potential practical significance of indicators with loadings lower than 0.70 was investigated. Thus, ten of the 28 measured variables from Figure 1 were dropped before accepting the final structural model because all of them had loadings lower than 0.70 , meaning they were not able to predict their respective constructs. 
Table 2. Measurement model evaluation results.

\begin{tabular}{|c|c|c|c|c|c|}
\hline Construct & Indicator & Loading & Cronbach Alpha & $\begin{array}{c}\text { Composite } \\
\text { Reliability (CR) }\end{array}$ & $\begin{array}{l}\text { Average Variance } \\
\text { Extracted (AVE) }\end{array}$ \\
\hline \multirow{4}{*}{ Flood characteristics (FC) } & FC1 & 0.767 & \multirow{4}{*}{0.862} & \multirow{4}{*}{0.906} & \multirow{4}{*}{0.708} \\
\hline & FC4 & 0.894 & & & \\
\hline & FC5 & 0.866 & & & \\
\hline & FC6 & 0.832 & & & \\
\hline \multirow{2}{*}{ Flood damage (FD) } & FD1 & 0.892 & \multirow{2}{*}{0.630} & \multirow[b]{2}{*}{0.705} & \multirow{2}{*}{0.557} \\
\hline & FD2 & 0.704 & & & \\
\hline \multirow{4}{*}{ Socio-economic condition (SE) } & SE1 & 0.969 & \multirow{4}{*}{0.660} & \multirow{4}{*}{0.795} & \multirow{4}{*}{0.507} \\
\hline & SE2 & 0.931 & & & \\
\hline & SE5 & 0.954 & & & \\
\hline & SE6 & 0.848 & & & \\
\hline \multirow{5}{*}{$\begin{array}{c}\text { Transport infrastructure } \\
\text { condition (TI) }\end{array}$} & TI2 & 0.910 & \multirow{5}{*}{0.647} & \multirow{5}{*}{0.766} & \multirow{5}{*}{0.563} \\
\hline & TI3 & 0.837 & & & \\
\hline & TI4 & 0.862 & & & \\
\hline & TI5 & 0.750 & & & \\
\hline & TI6 & 0.980 & & & \\
\hline \multirow{3}{*}{ Stakeholder attributes (SA) } & SA1 & 0.950 & \multirow{3}{*}{0.927} & \multirow{3}{*}{0.954} & \multirow{3}{*}{0.873} \\
\hline & SA2 & 0.939 & & & \\
\hline & SA3 & 0.914 & & & \\
\hline
\end{tabular}

The convergent validity of measurement models was evaluated based on (i) a composite reliability score and Cronbach's alpha, and (ii) the average variance extracted (AVE).

Table 2 shows Cronbach's alpha and the composite reliability generated by SmartPLS 2.0 software. Cronbach's alpha and composite reliability threshold values indicated that all the constructs had high levels of internal consistency reliability [55].

Table 2 also shows that the average variance extracted values were well above the required minimum level of 0.5 . The measures of reflective constructs, therefore, had high levels of convergent validity.

Finally, the results in Table 2 indicate that there was convergent validity and acceptable internal consistency in the measurement model, which reflects that the measurement indicators of each construct measured them well and were not measuring another construct.

The results in Table 2 indicate there are convergent validity and good internal consistency in the measurement model, which implies that the measurement indicators of each construct measured them well and were not measuring another construct.

\subsection{Analysis of Cross-Loadings}

The results of the cross-loading assessment in Table 3 indicate that all the 18 indicators loaded higher on the construct and, therefore, they demonstrated the discriminant validity of the constructs.

A cross-loading assessment was carried out using Smart-PLS 2.0 software; the results are illustrated in Table 3 and show that all the indicators loaded higher on the construct and they were theoretically specified to measure any other construct in the measurement models. This result indicates that all 18 indicators loaded distinctly on the specified construct they measured, and therefore demonstrated a discriminant validity of the constructs. 
Table 3. Cross-loading analysis.

\begin{tabular}{|c|c|c|c|c|c|}
\hline Indicator & $\begin{array}{l}\text { Flood Characteristics } \\
\text { (FC) }\end{array}$ & $\begin{array}{l}\text { Flood Damage } \\
\text { (FD) }\end{array}$ & $\begin{array}{l}\text { Socio-Economic } \\
\text { Condition (SE) }\end{array}$ & $\begin{array}{c}\text { Transport } \\
\text { Infrastructure (TI) }\end{array}$ & $\begin{array}{c}\text { Stakeholder } \\
\text { Attributes (SA) }\end{array}$ \\
\hline FC1 & 0.767 & 0.265 & 0.018 & 0.095 & 0.286 \\
\hline FC4 & 0.894 & 0.372 & 0.150 & 0.170 & -0.002 \\
\hline FC5 & 0.866 & 0.300 & 0.175 & 0.201 & 0.026 \\
\hline FC6 & 0.832 & 0.419 & 0.150 & 0.350 & 0.405 \\
\hline FD1 & 0.116 & 0.892 & 0.799 & 0.156 & 0.064 \\
\hline FD2 & 0.564 & 0.679 & 0.077 & 0.411 & 0.170 \\
\hline SE1 & 0.065 & -0.071 & 0.555 & -0.216 & -0.050 \\
\hline SE2 & -0.152 & -0.073 & 0.244 & -0.292 & -0.096 \\
\hline SE5 & 0.157 & 0.700 & 0.992 & 0.041 & 0.099 \\
\hline SE6 & 0.147 & 0.697 & 0.995 & 0.049 & 0.115 \\
\hline $\mathrm{TI} 2$ & 0.276 & 0.355 & 0.173 & 0.894 & -0.057 \\
\hline TI3 & 0.140 & 0.116 & -0.094 & 0.821 & 0.085 \\
\hline TI4 & 0.258 & 0.282 & 0.058 & 0.856 & 0.098 \\
\hline TI5 & 0.095 & 0.191 & 0.146 & 0.763 & 0.124 \\
\hline TI6 & 0.008 & 0.162 & 0.057 & 0.318 & 0.057 \\
\hline SA1 & 0.204 & 0.225 & 0.115 & 0.141 & 0.950 \\
\hline SA2 & 0.085 & 0.019 & 0.008 & 0.011 & 0.939 \\
\hline SA3 & 0.310 & 0.100 & 0.179 & -0.003 & 0.914 \\
\hline
\end{tabular}

Note: An indicator has the highest loading value (in bold) with the construct to which it has been assigned.

\subsection{Analysis of Average Variance Extracted}

Table 4 presents the correlation matrix for the constructs. There was no correlation identified between any two latent constructs that were larger than or even equal to the square root of these two constructs. This shows that the discriminant validity test did not display any serious predicament and indicated that all the constructs differed from each other.

Table 4. Fornell-Larcker criterion.

\begin{tabular}{ccccccc}
\hline Constructs & AVE & FC & FD & SE & TI & LA \\
\hline FC & 0.708 & $\mathbf{0 . 8 4 1}$ & & & & \\
FD & 0.557 & 0.414 & $\mathbf{0 . 7 4 6}$ & & & \\
SE & 0.507 & 0.154 & 0.701 & $\mathbf{0 . 7 1 2}$ & & \\
TI & 0.563 & 0.258 & 0.317 & 0.073 & $\mathbf{0 . 7 5 0}$ & \\
SA & 0.873 & 0.221 & 0.131 & 0.114 & 0.057 & $\mathbf{0 . 9 3 4}$ \\
\hline
\end{tabular}

Note: The diagonal elements (in bold) are the square root of the average variance extracted; nondiagonal elements are latent variable correlations.

\subsection{Evaluating Structural Model and Hypothesis Testing}

The significance of $t$-values associated with each path (hypothesis) was assessed using the Bootstrap procedure. Table 5 summarizes the path results and the corresponding t-values. Based on a significance level of $10 \%$ (1.65), hypotheses were considered to be supported [53].

Table 5. Results of hypothesis 1 testing.

\begin{tabular}{cccc}
\hline Relationship (Hypothesis) & Path Coefficient & $\boldsymbol{t}$-Value & Inference \\
\hline H1: Flood Characteristics $\rightarrow$ Flood Damage & +0.608 & +4.451 & Fully supported \\
\hline
\end{tabular}




\subsection{Analysis of Mediating Effects}

The indirect relationship explained the extent to which the variance of flood damage as a dependent variable was directly explained by stakeholder attributes as an independent variable. Table 6 shows that local councils' stakeholder attributes had a meaningful impact on the socio-economic and transport infrastructure conditions, which, in turn, had a robust relationship with flood damage. The indirect effect of stakeholder attributes (path coefficient of $0.724, p<0.01$ ) via the mediator construct-socio-economic conditionswas significant, whereas the direct relationship between stakeholder attributes and flood damage remained significant (path coefficient of $0.104, p<0.10$ ). Thus, the socio-economic condition fully mediated the relationship between stakeholder attributes and flood damage, which provided empirical support for Hypothesis 2a.

Table 6. Separate analysis for mediating effects.

\begin{tabular}{cccc}
\hline Constructs/Indicators & Total Effect & Bootstrap $t$-Statistic & VAF \\
\hline $\begin{array}{c}\text { H2a: Stakeholder attributes } \rightarrow \text { Flood damage } \\
\text { (via socio-economic condition) }\end{array}$ & $0.828^{* * *}$ & 3.07 & $87.44 \%$ \\
$\begin{array}{c}\text { H2b: Stakeholder attributes } \rightarrow \text { Flood damage } \\
\text { (via transport infrastructure condition) }\end{array}$ & $0.805^{* * *}$ & 2.25 & $\begin{array}{c}53.78 \% \\
\text { (partial mediation) }\end{array}$ \\
\hline
\end{tabular}

$(* * *<0.01)$.

Similarly, the indirect effect of stakeholder attributes (path coefficient of 0.433 , $p<0.01$ ) via the mediator construct-transport infrastructure-was also significant because the direct relationship between stakeholder attributes and flood damage also remained significant (path coefficient of $0.372, p<0.10$ ). Thus, the transport infrastructure condition partially mediated the relationship between stakeholder attributes and flood damage and provided empirical evidence for Hypothesis $2 \mathrm{~b}$. The findings presented in Table 6 could reflect that only local councils were included in the survey, and engaging other stakeholders such as state government planners, NGOs, and community groups might change the results.

The results of the structural model and hypotheses tests are shown in Figure 3. Based on the results of the structural equation modeling, the measurement model provides acceptable indicator reliability, convergent validity, and discriminant validity. Figure 3 shows that the constructs were within an acceptable level of error. Thus, the measurement model presents the sufficient robustness needed to test the relationship between the constructs required for a structural model evaluation. The results of the hypotheses tests are shown in Figure 3. 


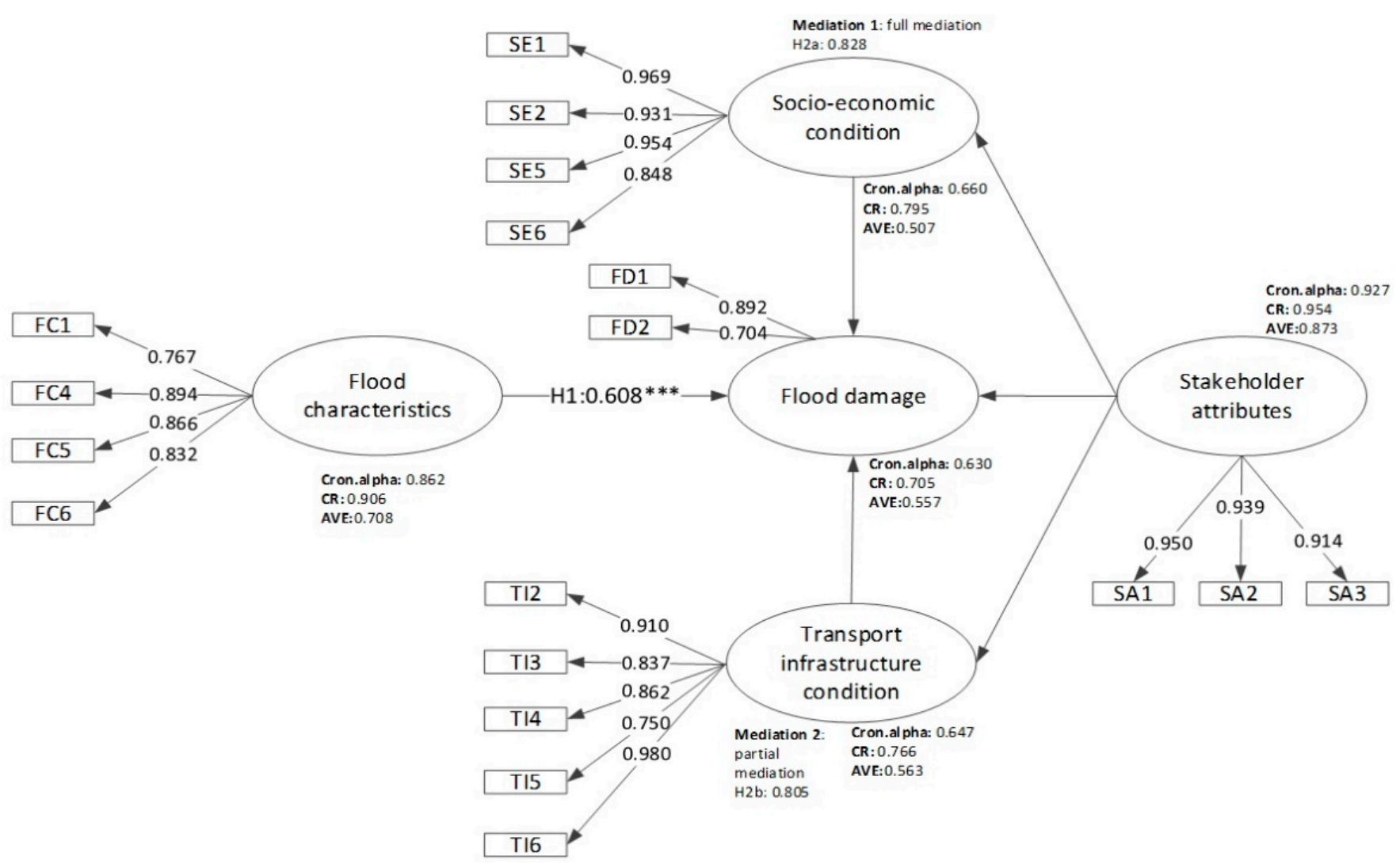

Figure 3. Results of structural model and hypotheses testing $\left({ }^{* * *} p<0.01\right)$.

\section{Discussion}

\subsection{The Effect of Flood Characteristics on Transport Infrastructure Damage}

The test results in Table 5 support hypothesis 1 that flood characteristics such as major flooding, rainfall annual mean, frequency of major flooding, and river flooding have a direct effect on the vulnerability of transport infrastructure components such as roads, bridges, culverts, and crossings to flood damage. A region with worse flood characteristics is more likely to have more flood damage. It was also emphasized that flood characteristics in Taiwan have a significant impact on flood damage, which are consistent with the findings of this study [32].

Transport infrastructure damage due to flooding in Australia is mainly associated with river flooding, and higher annual rainfall exacerbates the damage. River flooding is one of the most problematic types of floods, and economic flood damage has mostly been from river flooding [56]. The findings of this study also indicate that coastal areas are not as vulnerable as riverine areas. Finally, this study found that major flooding ( $\mathrm{FC1}$, factor loading $=0.767$ ), mean annual rainfall (FC4, factor loading $=0.894)$, frequency of major flooding $(\mathrm{FC} 5$, factor loading $=0.866)$, and river flooding $(\mathrm{FC} 6$, factor loading $=0.832)$ are the most significant measurement indicators for flood characteristics. For instance, local councils may be able to reduce the impact of socio-economic and transport infrastructure damage by minimizing the construction of roads and bridges close to flood-prone riverbanks. Local councils also need to have a comprehensive flood risk management plan for major flooding in the riverine areas and they also need to monitor rainfall for better flood forecasting, which is helpful for understanding flood risk, investing in flood risk reduction for resilience, and enhancing flood disaster preparedness for effective response and to build back better in post-flood reconstruction projects. 
6.2. The Role of Stakeholders' Attributes in Reducing Flood Damage Mediated by Socio-Economic and Road Infrastructure Conditions

Socio-economic exposure has a mediating effect on the direct relationship between local council attributes and flood damage. The indirect effect of stakeholder attributes (i.e., $0.724, p<0.01$ ) via socio-economic condition (mediator) was significant, while simultaneously, the direct relationship between stakeholder attributes and flood damage also remained significant (path coefficient of $0.104, p<0.10$; Table 6 ). Thus, the socio-economic condition fully mediated the relationship between stakeholder attributes and flood damage and provided empirical evidence for Hypothesis 2a. All three stakeholder attributes of power, legitimacy, and urgency are important for helping local councils to reduce flood risks; however, power has been identified as the more impactful factor. This means that the local council with more authority and power in resource allocation for flood risk management in their areas has shown better performance in managing flood risks. For example, the post-flood road reconstruction project recovery rate has been low in areas with powerful local councils compared with areas with poor stakeholder attributes. This finding further supports the idea of the Sendai Framework for Disaster Risk Reduction 205-2030, whose empowerment of local authorities and communities through resources, incentives, and decision-making responsibilities will reduce disaster risks [5].

The findings are consistent with previous research findings that claimed that reducing disaster risks was primarily moderated by the power of stakeholders and the availability of resources to cope with the impact of natural hazards. A possible explanation for this is that the effective preparedness, responses, and recovery in reducing disaster risks firmly depend on the institutional capacity of organizations who are engaged in disaster risk management. Therefore, stakeholders' organizational capacity is an essential criterion for mitigating the impact of flood risks and enhancing the resilience of the built environment, particularly critical road infrastructure.

Similarly, the transport infrastructure exposure has a mediating effect on the direct relationship between local council attributes and flood damage. The indirect effect of stakeholder attributes (i.e., $0.433, p<0.01$ ) via the mediator construct- transport infrastructurewas also significant, as was the direct relationship between stakeholder attributes and flood damage (path coefficient of $0.372, p<0.10$; see Table 6). Thus, the condition of transport infrastructure partially mediated the relationship between stakeholder attributes and flood damage and provided empirical evidence for Hypothesis $2 \mathrm{~b}$. A poor transport infrastructure condition with high exposure and vulnerability exacerbated the negative relationship between local councils' stakeholder attributes, particularly the power of local councils and flood damage.

\subsection{Benefits of Research Findings to Economy}

The direct benefit of this research is reducing economic losses caused by flood disasters in Australia. The research has a direct contribution to Australia's future economy because reducing the vulnerability of transport infrastructure to flooding risks leads to cost savings in disaster operations for Australian authorities. Importantly, this will help save the lives of Australian low-socio-economic-status citizens in flood situations and ultimately lead to a more resilient society and built environment in response to floods.

Managing stakeholders' attributes such as enhancing local governments' capabilities in managing flood risk through enhancing power, legitimacy, and urgency will decrease the exposure and vulnerability of socio-economic and transport infrastructure conditions against flood disasters, which will directly save a large amount of money for governments and society. Furthermore, the findings indicate that a region with higher local council stakeholder attributes (a powerful, legitimate, and urgent local council) is more likely to have less flood damage, although the socio-economic and transport infrastructure conditions of a region change the strength of this relationship. The federal government needs to allocate sufficient budget to strengthen local councils' stakeholder attributes and, at the same time, reduce the exposure of socio-economic and transport infrastructure 
conditions of a region. This is also in agreement with findings by [27] that stakeholder attributes are not the only indicators to predict the overall performance of stakeholder risk management approaches, and other external environmental factors should also be considered. To have significant benefits to the economy, local councils need to enhance their cooperation with each other, and State and Federal Governments need to prioritize the resource allocation to those local councils with lower stakeholder attributes. Local councils need to strengthen their technical and scientific capacity to capitalize on and consolidate existing knowledge and to develop and apply methodologies and models to assess flood risks.

\section{Conclusions}

In this paper, in order to address the first research objective, a conceptual framework was developed for the role of stakeholders' attributes in reducing flood damage to road infrastructure. It included five constructs: (1) flood characteristics (FC); (2) flood damage (FD); (3) socio-economic condition (SE); (4) transport infrastructure condition (TI); and (5) stakeholder attributes (SE). To address the second research objective, one hypothesis was developed and tested empirically. We found that flood characteristics have a positive direct effect on the vulnerability of roads and bridges to flood damage. In addition, local councils attributes of power, legitimacy, and urgency had a significant impact on the capacity of local councils to managing the economic impact of flood damage to transport infrastructure. Finally, to address the third research objective, two hypotheses were formulated, and we found that the socio-economic and transport infrastructure conditions mediated the relationship between stakeholder attributes and the vulnerability of roads and bridges to flood damage.

The empirical findings of this study have practical implications for policymakers, decisionmakers, and stakeholders who are engaged in managing flood risks in the built environment, particularly for resilient transport infrastructure planning. First, local councils should take necessary proactive actions in flood risk management to (i) control the zoning, location, and use of land to minimize the future construction of roads and bridges in areas prone to river flooding; (ii) develop engineering risk-based design standards for resilient transport infrastructure; and (iii) design comprehensive proactive flood risk management procedures, policies, and mandates. Second, the findings indicate that local councils need to upgrade nonurban unsealed roads to become resilient sealed roads and bridges. Third, the careful management of stakeholder attributes, such as strengthening power, legitimacy, and urgency, is essential for reducing the economic damage of floods to roads and bridges. Fourth, the observed or modeled relationship between the socio-economic condition and flood damage indicated that a wealthier local council is better equipped to manage flood risks, due to the higher Gross Regional Product per capita, higher income levels, and lower population density. Roads and bridges with higher exposure and vulnerability exacerbate the negative relationship between local councils' attributes and flood damage because more nonurban unsealed roads and bridges, including basins, barriers, culverts, levees, and drainage systems, are in some local areas, which makes those regions more vulnerable to low performance in project delivery. Fifth, it was found that local councils' attributes of power, legitimacy, and urgency have direct positive impacts on mitigation, preparedness, response, and recovery practices. By increasing the power, legitimacy, and urgency attributes of local councils, local councils would be better able to initiate mitigation activities in disaster risk reduction and preparedness, and implement response and recovery practices in disaster management more effectively.

This study also contributes to the body of knowledge in disaster risk management by discovering the mediating role played by the socio-economic and transport infrastructure conditions on the relationship between Local Councils' stakeholder attributes and flood damage. This study also examined the role of stakeholder theory in explaining stakeholder proactive and reactive approaches. Powerful, legitimate, and urgent stakeholders usually practice mitigation and preparedness activities in a proactive approach, but this study 
showed that local councils with a low level of power, legitimacy, and urgency in their decision-making process practice more response and recovery tasks in a reactive approach.

There are some limitations in this study that must be addressed in future studies. This study was based on historical data and survey responses from staff at 37 local councils in NSW. Future research could replicate the principal features of this study with a larger sample of different stakeholders in different states, regions, or countries. Further empirical investigations are needed to assess the impact of other relevant socio-economic variables. Another limitation of this study is the time horizon, which was between 1992 and 2014; however, the results are applicable to any timeframe in the future as well. Australia was selected as a case study in this research, which is another limitation, but it is highly suggested that other scholars investigate the same approach in other countries as a basis for a comparison analysis. This rich dataset is valuable for replication by studies of other researchers, including comparative studies with other collections of datasets from different countries.

Other types of built environments such as energy infrastructure, utility infrastructure, ports and airports, healthcare facilities, hospitals and residential and commercial buildings should be evaluated in further studies. This may offer new insight for researchers and practitioners into the effects of disaster risk management and other specific factors on stakeholders' approaches to managing disasters. This study developed a structural model based on stakeholder attributes as the pivotal construct identified from the literature. Future studies need to establish whether other capabilities of local councils, such as management, leadership, and governance, can alleviate the impact of disasters. Other stakeholders include state government planners, community groups, NGOs, developers, and the business community. It would be useful to investigate the links from transport infrastructure to other types of infrastructure that might be interdependent. The resilience, sustainability, and adaptability of infrastructure to climate should also be explored.

Author Contributions: Conceptualization, M.M. and B.L.O.; methodology, M.M. and B.L.O.; software, M.M.; validation, M.M.; formal analysis, M.M.; investigation, M.M.; resources, M.M.; writingoriginal draft preparation, M.M.; writing-review and editing, M.M. and B.L.O.; supervision, B.L.O. Both authors have read and agreed to the published version of the manuscript.

Funding: This research received no external funding.

Informed Consent Statement: Informed consent was obtained from all subjects involved in the study.

Data Availability Statement: Not applicable.

Conflicts of Interest: The authors declare no conflict of interest.

\section{References}

1. Wilby, R.L. A review of climate change impacts on the built environment. Built Environ. 2007, 33, 31-45. [CrossRef]

2. International Federation of Red Cross and Red Cresecent Societies. World Disaster Report; International Federation of Red Cross and Red Cresecent Societies: Geneva, Switzerland, 2015.

3. Markolf, S.A.; Hoehne, C.; Fraser, A.; Chester, M.V.; Underwood, B. Transportation resilience to climate change and extreme weather events-Beyond risk and robustness. Transp. Policy 2019, 74, 174-186. [CrossRef]

4. Opdyke, A.; Javernick-Will, A.; Koschmann, M. Infrastructure hazard resilience trends: An analysis of 25 years of research. Nat. Hazards 2017, 87, 773-789. [CrossRef]

5. United Nations Office for Disaster Risk Reduction. The Sendai Framework for Disaster Risk Reduction 2015-2030 Adopted at the Third UN World Conference in Sendai, Japan, on 18 March 2015; United Nations Office for Disaster Risk Reduction: Geneva, Switzerland, 2015.

6. Mojtahedi, S.M.H.; Oo, B.L. Coastal Buildings and Infrastructure Flood Risk Analysis using Multi-Attribute Decision-Making. J. Flood Risk Manag. 2014, 9, 87-96. [CrossRef]

7. Bosher, L.; Dainty, A.; Carrillo, P.; Glass, J.; Price, A. Attaining improved resilience to floods: A proactive multi-stakeholder approach. Disaster Prev. Manag. 2009, 18, 9-22. [CrossRef]

8. Mojtahedi, S.M.H.; Oo, B.L. Stakeholders' approaches to disaster risk reduction in built environment. Disaster Prev. Manag. 2014, 23, 356-369. [CrossRef]

9. Freeman, R.E. Strategic Management: A Stakeholder Approach; Pitman Publishing Imprint: Boston, MA, USA, 1984. 
10. Donaldson, T.; Preston, L.E. The stakeholder theory of the corporation: Concepts, evidence, and implications. Acad. Manag. Rev. 1995, 20, 65-91. [CrossRef]

11. Mitchell, R.K.; Agle, B.R.; Wood, D.J. Toward a theory of stakeholder identification and salience: Defining the principle of who and what really counts. Acad. Manag. 1997, 22, 853-886.

12. Phillips, R. Stakeholder legitimacy. Bus. Ethics Q. 2003, 13, 25-41. [CrossRef]

13. Bosher, L. Hazards and the Built Environment: Attaining Built-In Resilience; Routledge: New York, NY, USA, 2008.

14. Mojtahedi, M.; Oo, B.L. Critical attributes for proactive engagement of stakeholders in disaster risk management. Int. J. Disaster Risk Reduct. 2017, 21, 35-43. [CrossRef]

15. Mojtahedi, M.; Oo, B.L. The impact of stakeholder attributes on performance of disaster recovery projects: The case of transport infrastructure. Int. J. Proj. Manag. 2017, 35, 841-852. [CrossRef]

16. International Federation of Red Cross and Red Cresecent Societies. World Disaster Report 2018; International Federation of Red Cross and Red Cresecent Societies: Geneva, Switzerland, 2018.

17. Université Catholique de Louvain. EM-DAT. The OFDA/CRED International Disaster Database; Université Catholique de Louvain: Leuven, Belgium, 2018.

18. Setunge, S.; Lokuge, W.; Mohseni, H.; Karunasena, W. Vulnerability of Road Bridge Infrastructure; Australasian Fire and Emergency Service Authorities Council (AFAC): Melbourne, Australia, 2014.

19. Ladds, M.; Keating, A.; Handmer, J.; Magee, L. How much do disasters cost? A comparison of disaster cost estimates in Australia. Int. J. Disaster Risk Reduct. 2017, 21, 419-429. [CrossRef]

20. Pritchard, R.W. 2011 to 2012 Queensland floods and cyclone events: Lessons learnt for bridge transport infrastructure. Aust. J. Struct. Eng. 2013, 14, 167-176. [CrossRef]

21. Insurance Council of Australia (ICA). Damage Bill and Insurance Claim Update for Townsville Catastrophe; Insurance Council of Australia: Sydney, Australia, 2019. Available online: http:/ / www.insurancecouncil.com.au/media-centre?id=111 (accessed on 22 February 2019).

22. The Australian Institute for Disaster Resilience. Managing the Floodplain: A Guide to Best Practice in Flood Risk Management in Australia; Australian Government Attorney-General's Department: Melbourne, Australia, 2017.

23. Chen, Z.; Wang, Y. Impacts of severe weather events on high-speed rail and aviation delays. Transp. Res. D Transp. Environ. 2019, 69, 168-183. [CrossRef]

24. Rojek, A.; Little, M. Evacuating hospitals in Australia: What lessons can we learn from the world literature? Emerg. Med. Australas. 2013, 25, 496-502. [CrossRef]

25. Kinoshita, Y.; Tanoue, M.; Watanabe, S.; Hirabayashi, Y. Quantifying the effect of autonomous adaptation to global river flood projections: Application to future flood risk assessments. Environ. Res. Lett. 2018, 13, 014006. [CrossRef]

26. Oulahen, G.; Chang, S.E.; Yip, J.Z.; Conger, T.; Marteleira, M.; Carter, C. Contextualizing institutional factors in an indicator-based analysis of hazard vulnerability for coastal communities. J. Environ. Plan. Manag. 2017, 61, 2491-2511. [CrossRef]

27. Olander, S. Stakeholder impact analysis in construction project management. Constr. Manag. Econ. 2007, 25, 277-287. [CrossRef]

28. Rodríguez-Espíndola, O.; Albores, P.; Brewster, C. Disaster preparedness in humanitarian logistics: A collaborative approach for resource management in floods. Eur. J. Oper. Res. 2018, 264, 978-993. [CrossRef]

29. Moe, T.L.; Pathranarakul, P. An integrated approach to natural disaster management success factors. Disaster Prev. Manag. 2006, 15, 396-413.

30. Mysiak, J.; Castellari, S.; Kurnik, B.; Swart, R.; Pringle, P.; Schwarze, R.; Wolters, H.; Jeuken, A.; Van Der Linden, P. Brief communication: Strengthening coherence between climate change adaptation and disaster risk reduction. Nat. Hazards Earth Syst. Sci. 2018, 18, 3137-3143. [CrossRef]

31. Leroy, S.A. From natural hazard to environmental catastrophe: Past and present. Quat. Int. 2006, 158, 4-12. [CrossRef]

32. Ho, M.-C.; Shaw, D.; Lin, S.; Chiu, Y.-C. How Do Disaster Characteristics Influence Risk Perception? Risk Anal. 2008, 28 , 635-643. [CrossRef] [PubMed]

33. Merz, B.; Kreibich, H.; Thieken, A.; Schmidtke, R. Estimation uncertainty of direct monetary flood damage to buildings. Nat. Hazards Earth Syst. Sci. 2004, 4, 153-163. [CrossRef]

34. Balica, S.F.; Wright, N.; Van Der Meulen, F. A flood vulnerability index for coastal cities and its use in assessing climate change impacts. Nat. Hazards 2012, 64, 73-105. [CrossRef]

35. Emergency Management Australia. Managing the Floodplain; Emergency Management Australia: Canberra, Australia, 1999.

36. Mirfenderesk, H. Flood emergency management decision support system on the Gold Coast, Australia. Aust. J. Emerg. Manag. 2009, 24, 48-58.

37. Fraume, M.-C.M.; Cardona Arboleda, O.-D.; Fraume, P.M.; T, M.-L.C.; Barbat, A.H. Evaluating risk from a holistic perspective to improve resilience: The United Nations evaluation at global level. Saf. Sci. 2020, 127, 104739. [CrossRef]

38. Van Ginkel, K.C.H.; Botzen, W.J.W.; Haasnoot, M.; Bachner, G.; Steininger, K.W.; Hinkel, J.; Watkiss, P.; Boere, E.; Jeuken, A.; De Murieta, E.S.; et al. Climate change induced socio-economic tipping points: Review and stakeholder consultation for policy relevant research. Environ. Res. Lett. 2020, 15, 023001. [CrossRef]

39. Doktycz, C.; Abkowitz, M. Loss and Damage Estimation for Extreme Weather Events: State of the Practice. Sustainability 2019, 11, 4243. [CrossRef] 
40. Lowe, D.; Ebi, K.L.; Forsberg, B. Factors increasing vulnerability to health effects before, during and after floods. Int. J. Environ. Res. Public Health 2013, 10, 7015-7067. [CrossRef]

41. Achillopoulou, D.V.; Mitoulis, S.A.; Argyroudis, S.; Wang, Y. Monitoring of transport infrastructure exposed to multiple hazards: A roadmap for building resilience. Sci. Total. Environ. 2020, 746, 141001. [CrossRef] [PubMed]

42. Bosher, L.; Chmutina, K. Disaster Risk Reduction for the Built Environment; Wiley-Blackwell: Hoboken, NJ, USA, 2017.

43. Vetrivel, A.; Gerke, M.; Kerle, N.; Nex, F.; Vosselman, G. Disaster damage detection through synergistic use of deep learning and 3D point cloud features derived from very high resolution oblique aerial images, and multiple-kernel-learning. ISPRS J. Photogramm. Remote Sens. 2018, 140, 45-59. [CrossRef]

44. De Silva, M.; Kawasaki, A. Socioeconomic Vulnerability to Disaster Risk: A Case Study of Flood and Drought Impact in a Rural Sri Lankan Community. Ecol. Econ. 2018, 152, 131-140. [CrossRef]

45. Fatemi, F.; Ardalan, A.; Aguirre, B.; Mansouri, N.; Mohammadfam, I. Social vulnerability indicators in disasters: Findings from a systematic review. Int. J. Disaster Risk Reduct. 2017, 22, 219-227. [CrossRef]

46. Dalezios, N.R.; Petropoulos, G.P.; Faraslis, I.N. Concepts and Methodologies of Environmental Hazards and Disasters. In Techniques for Disaster Risk Management and Mitigation; John Wiley \& Sons, Inc.: Hoboken, NJ, USA, 2020; pp. 1-22.

47. Bureau of Transport Economics. Economic Costs of Natural Disasters in Australia; Report 103; Bureau of Transport Economics: Canberra, Australia, 2001.

48. Creswell, J.W. Research Design: Qualitative, Quantitative, and Mixed Methods Approaches; Sage: Newcastle upon Tyne, UK, 2013.

49. Sarstedt, M.; Cheah, J.H. Partial least squares structural equation modeling using SmartPLS: A software review. J. Mark. Anal. 2019, 7, 196-202. [CrossRef]

50. Sinkovics, R.R.; Henseler, J.; Ringle, C.M.; Sarstedt, M. Testing measurement invariance of composites using partial least squares. Int. Mark. Rev. 2016, 33, 405-431.

51. Cook, T.D.; Campbell, D.T.; Day, A. Quasi-Experimentation: Design E Analysis Issues for Field Settings; Houghton Mifflin: Boston, MA, USA, 1979.

52. Campbell, D.T.; Fiske, D.W. Convergent and discriminant validation by the multitrait-multimethod matrix. Psychol. Bull. 1959, 56, 81. [CrossRef] [PubMed]

53. Hair, J.F.; Hult, G.T.M.; Ringle, C.; Sarstedt, M. A Primer on Partial Least Squares Structural Equation Modeling (PLS-SEM); SAGE Publications, Inc.: Thousand Oaks, CA, USA, 2014.

54. Hulland, J. Use of partial least squares (PLS) in strategic management research: A review of four recent studies. Strateg. Manag. J. 1999, 20, 195-204. [CrossRef]

55. Churchill, G.A. A paradigm for developing better measures of marketing constructs. J. Mark. Res. 1979, 16, 64-73. [CrossRef]

56. Mckenzie, E.; Prasad, B.C.; Kaloumaira, A. Economic Assessment Tools. In Economic Impact of Natural Disasters on Development in the Pacific; AusAID: Canberra, Australia, 2005. 